\title{
Cerium oxide nanoparticles protect against $A \beta$-induced mitochondrial fragmentation and neuronal cell death
}

\author{
JM Dowding ${ }^{1}$, W Song ${ }^{1}$, K Bossy $^{1}$, A Karakoti ${ }^{2}$, A Kumar ${ }^{3}$, A Kim ${ }^{4}$, B Bossy ${ }^{1}$, S Seal ${ }^{3}$, MH Ellisman ${ }^{4}$, G Perkins ${ }^{4}$, WT Self ${ }^{\star}, 1$ \\ and E Bossy-Wetzel ${ }^{*, 1}$
}

Evidence indicates that nitrosative stress and mitochondrial dysfunction participate in the pathogenesis of Alzheimer's disease $(A D)$. Amyloid beta $(A \beta)$ and peroxynitrite induce mitochondrial fragmentation and neuronal cell death by abnormal activation of dynamin-related protein 1 (DRP1), a large GTPase that regulates mitochondrial fission. The exact mechanisms of mitochondrial fragmentation and DRP1 overactivation in AD remain unknown; however, DRP1 serine 616 (S616) phosphorylation is likely involved. Although it is clear that nitrosative stress caused by peroxynitrite has a role in $A D$, effective antioxidant therapies are lacking. Cerium oxide nanoparticles, or nanoceria, switch between their $\mathrm{Ce}^{3+}$ and $\mathrm{Ce}^{4+}$ states and are able to scavenge superoxide anions, hydrogen peroxide and peroxynitrite. Therefore, nanoceria might protect against neurodegeneration. Here we report that nanoceria are internalized by neurons and accumulate at the mitochondrial outer membrane and plasma membrane. Furthermore, nanoceria reduce levels of reactive nitrogen species and protein tyrosine nitration in neurons exposed to peroxynitrite. Importantly, nanoceria reduce endogenous peroxynitrite and A $\beta$-induced mitochondrial fragmentation, DRP1 S616 hyperphosphorylation and neuronal cell death.

Cell Death and Differentiation (2014) 21, 1622-1632; doi:10.1038/cdd.2014.72; published online 6 June 2014

Nitric oxide (NO) is a neurotransmitter and neuromodulator required for learning and memory. ${ }^{1} \mathrm{NO}$ is generated by $\mathrm{NO}$ synthases, a group of enzymes that produce NO from $\mathrm{L}$-arginine. In addition to its normal role in physiology, NO is implicated in pathophysiology. When overproduced, NO combines with superoxide anions $\left(\mathrm{O}_{2}{ }^{-}\right)$, byproducts of aerobic metabolism and mitochondrial oxidative phosphorylation, to form peroxynitrite anions $\left(\mathrm{ONOO}^{-}\right)$that are highly reactive and neurotoxic. Accumulation of these reactive oxygen species (ROS) and reactive nitrogen species (RNS), known as oxidative and nitrosative stress, respectively, is a common feature of aging, neurodegeneration and Alzheimer's disease (AD). ${ }^{1}$

Nitrosative stress caused by peroxynitrite has a critical role in the etiology and pathogenesis of $A D .^{2-7}$ Peroxynitrite is implicated in the formation of the two hallmarks of $A D, A \beta$ aggregates and neurofibrillary tangles containing hyperphosphorylated Tau protein. ${ }^{1,4,7}$ In addition, peroxynitrite promotes the nitrotyrosination of presenilin 1, the catalytic subunit of the $\gamma$-secretase complex, which shifts production of $\mathrm{A} \beta$ to amyloid beta $(\mathrm{A} \beta) 42$ and increases the $\mathrm{A} \beta 42 / \mathrm{A} \beta 40$ ratio, ultimately resulting in an increased propensity for aggregation and neurotoxicity. ${ }^{5}$ Furthermore, nitration of $\mathrm{A} \beta$ tyrosine 10 enhances its aggregation. ${ }^{6}$ Peroxynitrite can also modify enzymes, such as triosephosphate isomerase, ${ }^{4}$ and activate kinases, including Jun amino-terminal kinase and p38 mitogen-activated protein kinase, which enhance neuronal cell death. ${ }^{8,9}$ Moreover, peroxynitrite can trigger the release of free metals such as $\mathrm{Zn}^{2+}$ from intracellular stores with consequent inhibition of mitochondrial function and enhancement of neuronal cell death. ${ }^{10-12}$ Finally, peroxynitrite can irreversibly inhibit complexes I and IV of the mitochondrial respiratory chain. ${ }^{11,13}$

Because mitochondria have a critical role in neurons as energy producers to fuel vital processes such as synaptic transmission and axonal transport, ${ }^{14}$ and mitochondrial dysfunction is a well-documented and early event in $A D,{ }^{15}$ it is important to consider how peroxynitrite and nitrosative stress affect mitochondria. Although the ultimate cause of mitochondrial dysfunction in $A D$ remains unclear, an imbalance in mitochondrial fission and fusion is one possibility. ${ }^{1,14,16-18}$ Notably, peroxynitrite, $N$-methyl $D$-aspartate (NMDA) receptor activation and $\mathrm{A} \beta$ can induce mitochondrial fragmentation by activating mitochondrial fission and/or

${ }^{1}$ Burnett School of Biomedical Sciences, College of Medicine, University of Central Florida, Orlando, FL 32816, USA; ${ }^{2}$ Environmental and Molecular Sciences Laboratory, Pacific Northwest National Laboratory, Richland, WA 99354, USA; ${ }^{3}$ Advanced Materials Processing and Analysis Center, Mechanical Material and Aerospace Engineering, Nanoscience and Technology Center (NSTC), University of Central Florida, Orlando, FL 32816, USA and ${ }^{4}$ National Center for Microscopy and Imaging Research, School of Medicine, University of California, San Diego, La Jolla, CA 92093-060, USA

${ }^{*}$ Corresponding authors: E Bossy-Wetzel, Burnett School of Biomedical Sciences, College of Medicine, University of Central Florida, Orlando, FL 32816, USA. Tel: +1 407823 3384; Fax: +1 407823 0956; E-mail: Ella.Bossy-Wetzel@ucf.edu

or WT Self, Burnett School of Biomedical Sciences, College of Medicine, University of Central Florida, Orlando, FL 32816, USA. Tel: +1 407 823 4262; Fax: +1 407823 0956; E-mail: William.Self@ucf.edu

Abbreviations: $A \beta$, amyloid beta; $A D$, Alzheimer's disease; APF, 3'-(p-aminophenyl) fluorescein; $\mathrm{H}_{2} \mathrm{O}_{2}$, hydrogen peroxide; $\mathrm{CeO}_{2}$, cerium oxide; DRP1, dynaminrelated protein 1; DTPA, diethylenetriaminepentaacetic acid; NAC, N-acetyl-L-cysteine; NMDA, N-methyl D-aspartate; NO, nitric oxide; 3-NP, 3-nitropropionic acid; 3-NT, 3-nitrotyrosine; ROS, reactive oxygen species; RNS, reactive nitrogen species; RT, room temperature; SNOC, S-nitrosocysteine; SOD, superoxide dismutase Received 02.8.12; revised 21.4.14; accepted 22.4.14; Edited by M Deshmukh; published online 06.6.14 
inhibiting fusion. ${ }^{16}$ Mitochondrial fission and fusion is regulated by large GTPases of the dynamin family, including dynamin-related protein 1 (DRP1) that is required for mitochondrial division, ${ }^{19}$ and inhibition of mitochondrial division by overexpression of the GTPase-defective $\mathrm{DRP} 1^{\mathrm{K} 38 \mathrm{~A}}$ mutant provides protection against peroxynitrite-, NMDA- and $\mathrm{A} \beta$-induced mitochondrial fragmentation and neuronal cell death. ${ }^{16}$

The exact mechanism of peroxynitrite-induced mitochondrial fragmentation remains unclear. A recent report suggested that S-nitrosylation of DRP1 at cysteine 644 increases DRP1 activity and is the cause of peroxynitriteinduced mitochondrial fragmentation in $A D ;{ }^{20}$ however, the work remains controversial, suggesting that alternative pathways might be involved. ${ }^{21}$ For example, peroxynitrite also causes rapid DRP1 S616 phosphorylation that promotes its translocation to mitochondria and organelle division. ${ }^{21,22}$ In mitotic cells, DRP1 S616 phosphorylation is mediated by Cdk1/cyclinB1 and synchronizes mitochondrial division with cell division. ${ }^{23}$ Interestingly, DRP1 is S616 hyperphosphorylated in AD brains, suggesting that this event might contribute to mitochondrial fragmentation in the disease. ${ }^{21,22} A$ recent report indicates that $\mathrm{Cdk5/p35}$ is responsible for DRP1 S616 phosphorylation, ${ }^{24}$ and notably aberrant Cdk5/p35/p25 signaling is associated with $A D$ pathogenesis. ${ }^{25}$ Thus, we explored here the possible role of DRP1 S616 hyperphosphorylation in $\mathrm{A} \beta$ - and peroxynitrite-mediated mitochondrial fragmentation.

Under normal conditions, accumulated mitochondrial superoxide anions and hydrogen peroxide $\left(\mathrm{H}_{2} \mathrm{O}_{2}\right)$ can be neutralized by superoxide dismutase (SOD) and catalase. Nitrosative stress in aging and AD might be explained by a loss of antioxidant enzymes. Previous studies suggest that expression of SOD subtypes is decreased in the human AD brain. ${ }^{26,27}$ Furthermore, SOD1 deletion in a mouse model of $\mathrm{AD}$ increased the burden of amyloid plaques. ${ }^{26}$ By contrast, overexpression of SOD2 in a mouse model of AD decreased the $\mathrm{A} \beta 42 / \mathrm{A} \beta 40$ ratio and alleviated memory deficits. ${ }^{28,29}$ There is currently a lack of antioxidants that can effectively quench superoxide anions, $\mathrm{H}_{2} \mathrm{O}_{2}$ or peroxynitrite and provide lasting effects. Cerium is a rare earth element and cerium oxide $\left(\mathrm{CeO}_{2}\right)$ nanoparticles, or nanoceria, shuttle between their $3+$ or $4+$ states. Oxidation of $\mathrm{Ce}^{4+}$ to $\mathrm{Ce}^{3+}$ causes oxygen vacancies and defects on the surface of the crystalline lattice structure of the nanoparticles, generating a cage for redox reactions to occur. ${ }^{30}$ Accordingly, nanoceria mimic the catalytic activities of antioxidant enzymes, such as $\mathrm{SOD}^{31,32}$ and catalase, ${ }^{33}$ and are able to neutralize peroxynitrite. ${ }^{34}$ Because of these antioxidant properties, we hypothesized that nanoceria could detoxify peroxynitrite and protect against A $\beta$-induced DRP1 S616 hyperphosphorylation, mitochondrial fragmentation and neuronal cell death.

\section{Results}

Nanoceria accumulate at mitochondria in neurons. We first determined the physical properties of our nanoceria preparation and confirmed their $\mathrm{Ce}^{3+}$ state, fluorite structure and cerium spectrum (Supplementary Figure 1). Nanoceria are internalized by cultured cells because of their small size
( $\sim 3$ to $8 \mathrm{~nm})^{35,36}$ however, their subcellular localization in neurons remains unclear. Therefore, we tracked the presence of nanoceria in primary rat cortical neurons using transmission electron microscopy (TEM). Although untreated neurons exhibited no signal (Figure 1a), we obtained evidence of electron-dense particles in neurons cultured with nanoceria for 3 or $12 \mathrm{~h}$. Specifically, nanoceria were present at two locations: the mitochondrial outer membrane and inner leaflet of the plasma membrane (Figures $1 \mathrm{~b}$ and $\mathrm{c}$ ). To verify that the electron-dense granules were indeed nanoceria, we repeated the EM preparation using samples void of post staining. Using this modification, we still detected electron-dense particles, suggesting that they were not an artifact and were indeed the nanoparticles (Figure 1d). The nanoparticles were $\sim 3$ to $8 \mathrm{~nm}$ in size (Figure 1e), in agreement with previous reports. ${ }^{37}$ The electron-dense particles within neurons were larger, measuring $20.6 \mathrm{~nm}$ $( \pm 2.9 \mathrm{~nm}$ S.D.). The increased size is expected as nanoparticles agglomerate in cells because of their surface interactions with biological materials. Further quantification of the association of nanoceria particles with mitochondria (Figure 1f) or the plasma membrane (Figure 1g) suggested that their location aligns with sites of increased ROS and RNS production in neurons. Analyses of the nuclei revealed very few nanoceria (data not shown).

Nanoceria protect against nitrosative stress. Peroxynitrite is implicated in $\mathrm{AD}^{2,3,7}$ We therefore tested whether nanoceria could reduce nitrosative stress in neurons treated with the exogenous NO donor S-nitrosocysteine (SNOC). Peroxynitrite was measured by live-cell imaging using $3^{\prime}$-( $p$-aminophenyl) fluorescein (APF) and fluorescence microscopy. Control neurons exposed to either aged SNOC, which released all NO because of its poor stability, or nanoceria alone displayed low background APF fluorescence (Figures 2A(a) and (b)). By contrast, neurons exposed to freshly prepared SNOC exhibited a clear increase in fluorescence, reflecting APF oxidation (Figure $2 \mathrm{~A}(\mathrm{c})$. Importantly, pretreatment of neurons with nanoceria for $3 \mathrm{~h}$ abolished the SNOC-induced increase in APF fluorescence, suggesting that nanoceria were able to neutralize peroxynitrite (Figures 2A(c) and (d)). Notably, the APF fluorescent signal in SNOC-exposed neurons revealed a mottled cytoplasmic pattern (Figure $2 \mathrm{~A}(\mathrm{c})$ )). It is possible that APF marks mitochondria with increased peroxynitrite levels. Further quantitative analyses confirmed a decrease in APF oxidation in neurons treated with fresh SNOC and nanoceria compared with neurons treated with SNOC alone (Figure 2B). Finally, nanoceria protected neurons from SNOC-induced cell death (Figure 2C).

Nanoceria reduce peroxynitrite-mediated tyrosine nitration. Peroxynitrite-mediated protein tyrosine nitration occurs in $A D$; therefore, protein tyrosine nitration can be used as marker for neurodegeneration. ${ }^{7}$ We therefore tested whether nanoceria reduced SNOC-mediated protein tyrosine nitration by immunocytochemistry using anti-nitrotyrosine antibodies. We observed that control neurons treated with either aged SNOC or nanoceria alone exhibited low background nitrotyrosine immunofluorescence (Figures $3 A(a)$ and (b)). 

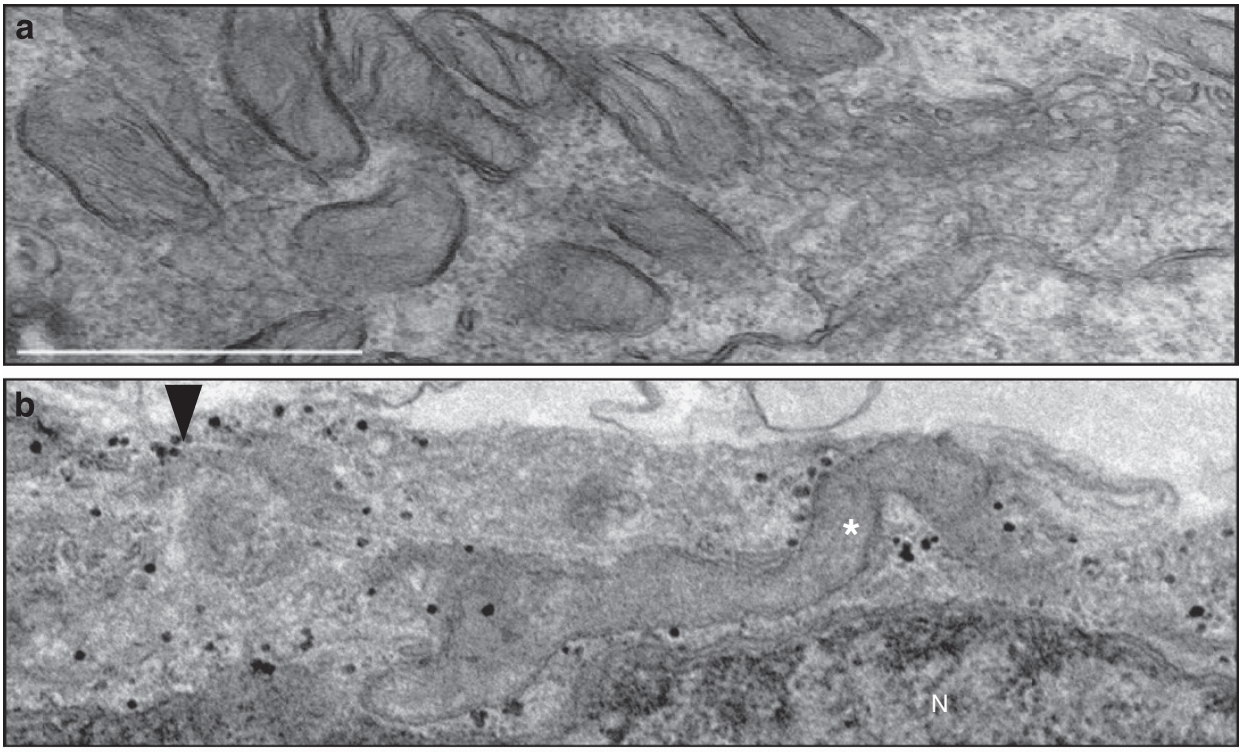

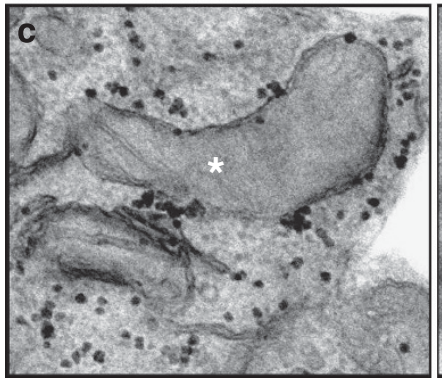

f

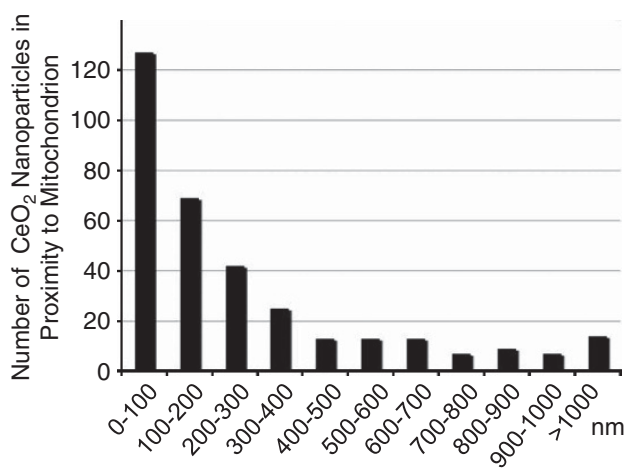

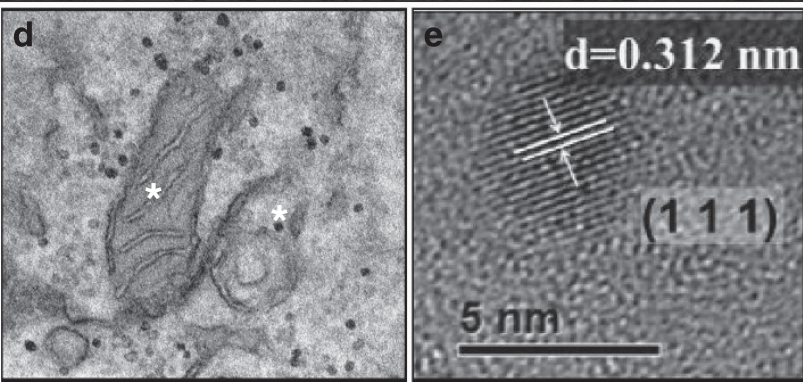

g

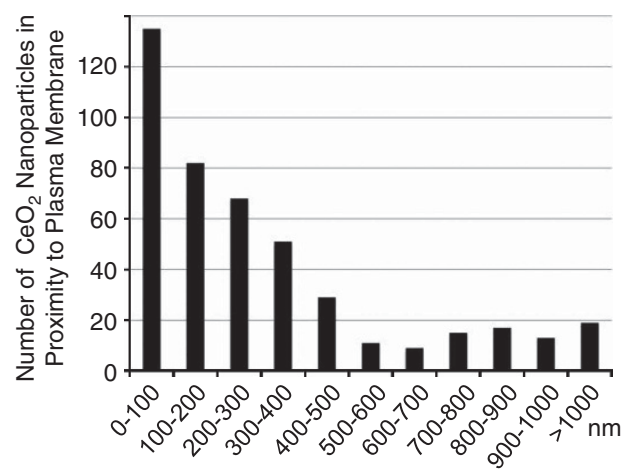

Figure 1 Nanoceria accumulate at the mitochondrial outer mitochondria and the inner leaflet of the plasma membrane in cultured cortical neurons. (a) Electron microscopy of an untreated control neuron. Scale bar, $1 \mu \mathrm{m}$. (b) Electron microscopy of a neuron treated with $\mathrm{CeO}_{2}$ nanoparticles ( $100 \mathrm{nM}$ ) for $3 \mathrm{~h}$. Round electron-dense particles, indicative of nanoceria particles, concentrate around mitochondria (*) and the plasma membrane (black arrowhead), but not along the nucleus (N). (c) Electron microscopy of a neuron treated with $\mathrm{CeO}_{2}$ nanoparticles $(100 \mathrm{nM})$ for $12 \mathrm{~h}$. Mitochondrion (*) showing clusters of nanoceria particles accumulating at the mitochondrial outer membrane. (d) Electron microscopy of a neuron treated with $\mathrm{CeO}_{2}$ nanoparticles $(100 \mathrm{nM})$ for $3 \mathrm{~h}$ for which the post-staining step was omitted. The mitochondrion is marked with the $\left(^{*}\right)$ symbol. (e) HRTEM of a nanoceria particle. Parallel lines indicate the inter-planar spacing of the atomic arrangement ' $\mathrm{d}$ ' showing the ceria lattice distance of $0.312 \mathrm{~nm}$ (as measured by the diffraction pattern; Supplementary Figure 1c) and a Miller index of (111). Scale bar, $5 \mathrm{~nm}$. (f and $\mathbf{g}$ ) Bar graphs showing number of nanoceria particles in proximity to the mitochondrial outer membrane (f) or inner leaflet of the plasma membrane (g). The closest distance between a nanoceria particle and a mitochondrion or the plasma membrane was measured with Image $\mathrm{J}$ and then binned in $100 \mathrm{~nm}$ increments

By contrast, neurons exposed to fresh SNOC exhibited an increase in fluorescence, reflecting increased protein tyrosine nitration (Figure $3 \mathrm{~A}(\mathrm{c})$ ). Remarkably, nanoceria prevented SNOC-induced tyrosine nitration, as evidenced by reduced fluorescence intensity (Figure 3A(d)). Quantitative analyses confirmed a significant reduction in the relative nitrotyrosine signal in neurons pretreated with nanoceria (Figure 3B). Finally, we analyzed the relative nitrotyrosine immunoreactivity of neuronal cell lysates by immune blotting. Again, nanoceria reduced SNOC-mediated global protein tyrosine nitration, confirming our data in intact neurons (Figure 3C). 

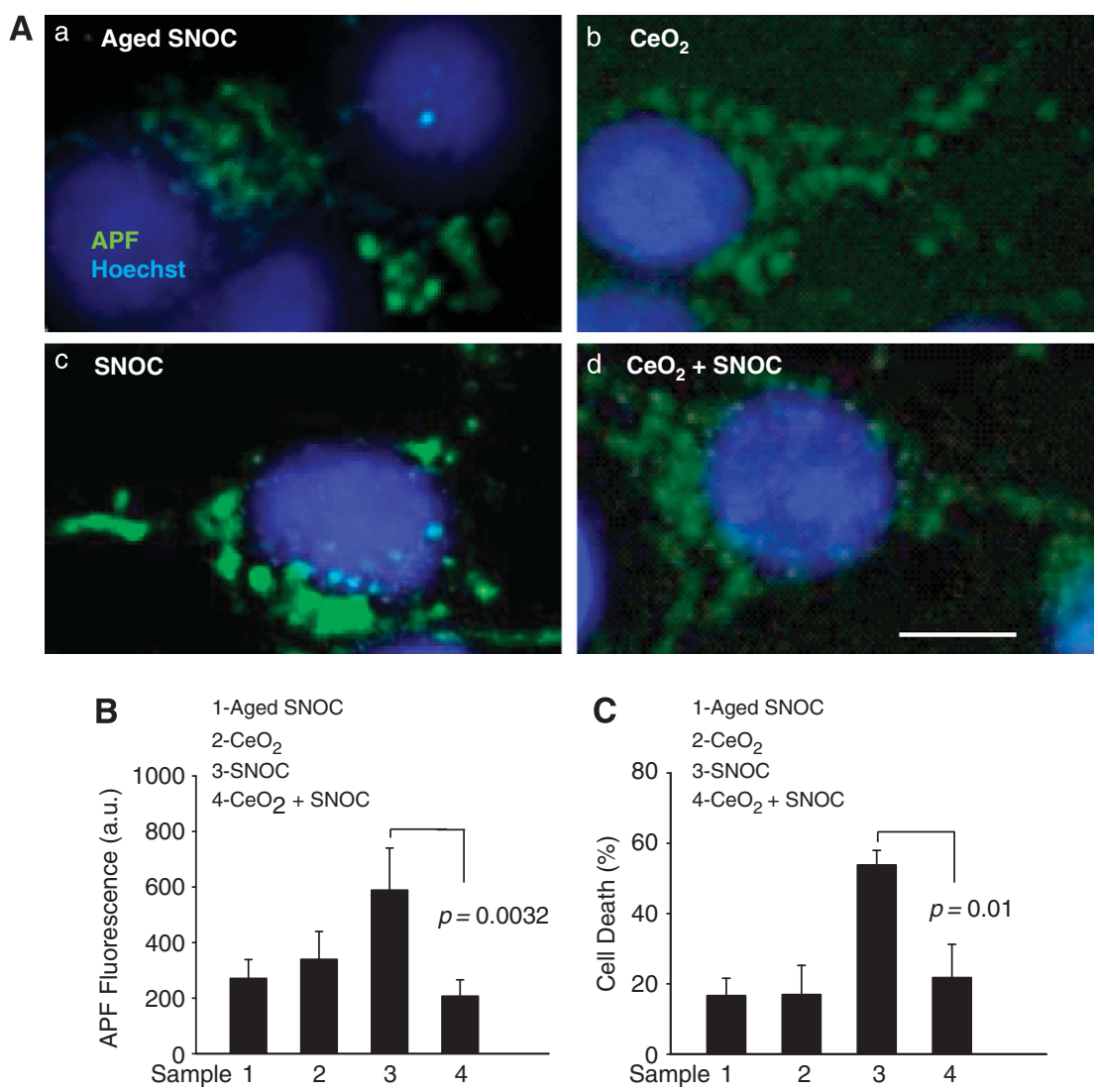

Figure 2 Nanoceria scavenge RNS and rescue cortical neurons from SNOC-induced cell death. (A) Fluorescence images of APF (green) and Hoechst 33342 (blue) double staining of neurons treated with (a) aged SNOC $(100 \mu \mathrm{M})$, (b) nanoceria $(100 \mathrm{nM})$, (c) fresh SNOC $(100 \mu \mathrm{M})$ or (d) both nanoceria $(100 \mathrm{nM})$ and fresh SNOC $(100 \mu \mathrm{M})$ for $2 \mathrm{~h}$. Scale bar, $10 \mu \mathrm{m}$. (B) APF fluorescence of neurons treated with aged SNOC, nanoceria or fresh SNOC alone or a combination of nanoceria and fresh SNOC for $2 \mathrm{~h}$. (C) Cell death of neurons (at $3 \mathrm{~h}$ ) treated with aged SNOC, nanoceria or fresh SNOC alone or a combination of nanoceria and fresh SNOC. Data represent means \pm S.D. Results are representative of three or more independent experiments. Statistics: Student's $t$-test

Nanoceria protect against $A \beta$-induced mitochondrial fragmentation. $\mathrm{A} \beta$ signaling is linked with peroxynitrite production. $^{1,15} \mathrm{~A} \beta$ or peroxynitrite trigger mitochondrial fragmentation, which in turn can lead to bioenergetic failure, impaired $\mathrm{Ca}^{2+}$ homeostasis, synaptic injury, axonal transport defects and neuronal cell death. ${ }^{16,20}$ To investigate whether nanoceria would prevent A $\beta$-mediated mitochondrial fragmentation, mitochondrial morphology was visualized by fluorescence microscopy in transfected neurons expressing DsRed2-Mito. Control neurons, either left untreated or treated with nanoceria alone for $3 \mathrm{~h}$, exhibited an elongated mitochondrial morphology typical of healthy neurons (Figures $4 \mathrm{~A}(\mathrm{a})$ and (b)). By contrast, $A \beta_{25-35}$ peptide (Figure $4 A(c)$ ), but not the reverse $A \beta_{35-25}$ control peptide (Figure $4 A(g)$ ), induced marked mitochondrial fragmentation as evidenced by the appearance of rounded mitochondria. Remarkably, nanoceria prevented $\mathrm{A} \beta_{25-35}$-induced mitochondrial fragmentation, similar to $N$-acetyl-L-cysteine (NAC), a peroxynitrite neutralizing antioxidant (Figures $4 A(d-f)$ ). Quantitative analysis confirmed that nanoceria reduced $\mathrm{A} \beta$-induced mitochondrial fragmentation (Figure 4B).

Nanoceria reduce DRP1 phosphorylation at $\mathbf{S 6 1 6 .}$ Mitochondrial fragmentation resulting from excessive
DRP1-dependent mitochondrial fission is linked to neurodegeneration and $\mathrm{AD} .{ }^{14,22}$ We previously demonstrated that SNOC can trigger DRP1 S616 phosphorylation and mitochondrial fragmentation. ${ }^{16,21}$ Furthermore, DRP1 is hyperphosphorylated on S616 in AD patient brains. ${ }^{21,22}$ Because nanoceria were able to prevent $A \beta$-induced mitochondrial fragmentation (Figure 4), we next investigated whether they could also inhibit DRP1 S616 phosphorylation, providing a potential mechanistic explanation for the observed mitochondrial preservation. Neurons treated with either aged SNOC or nanoceria alone exhibited low baseline DRP1 S616 phosphorylation (Figure 5a). By contrast, neurons treated with fresh NO donor exhibited increased levels of DRP1 S616 phosphorylation (Figure 5a). Nanoceria reduced the SNOC-induced increase in DRP1 S616 phosphorylation (Figure 5a). Similarly, nanoceria or NAC abolished $\mathrm{A} / 25-35$-induced DRP1 S616 phosphorylation (Figure 5b).

Nanoceria protect against $A \beta$-induced neuronal cell death. Neuronal cell death caused by $\mathrm{A} \beta$, NMDA or the mitochondrial respiratory complex II inhibitor 3-nitropropionic acid (3-NP) occurs, at least in part, because of endogenous peroxynitrite production. ${ }^{16,38}$ We therefore tested whether nanoceria could inhibit neuronal cell death caused by these neurotoxic stimuli 

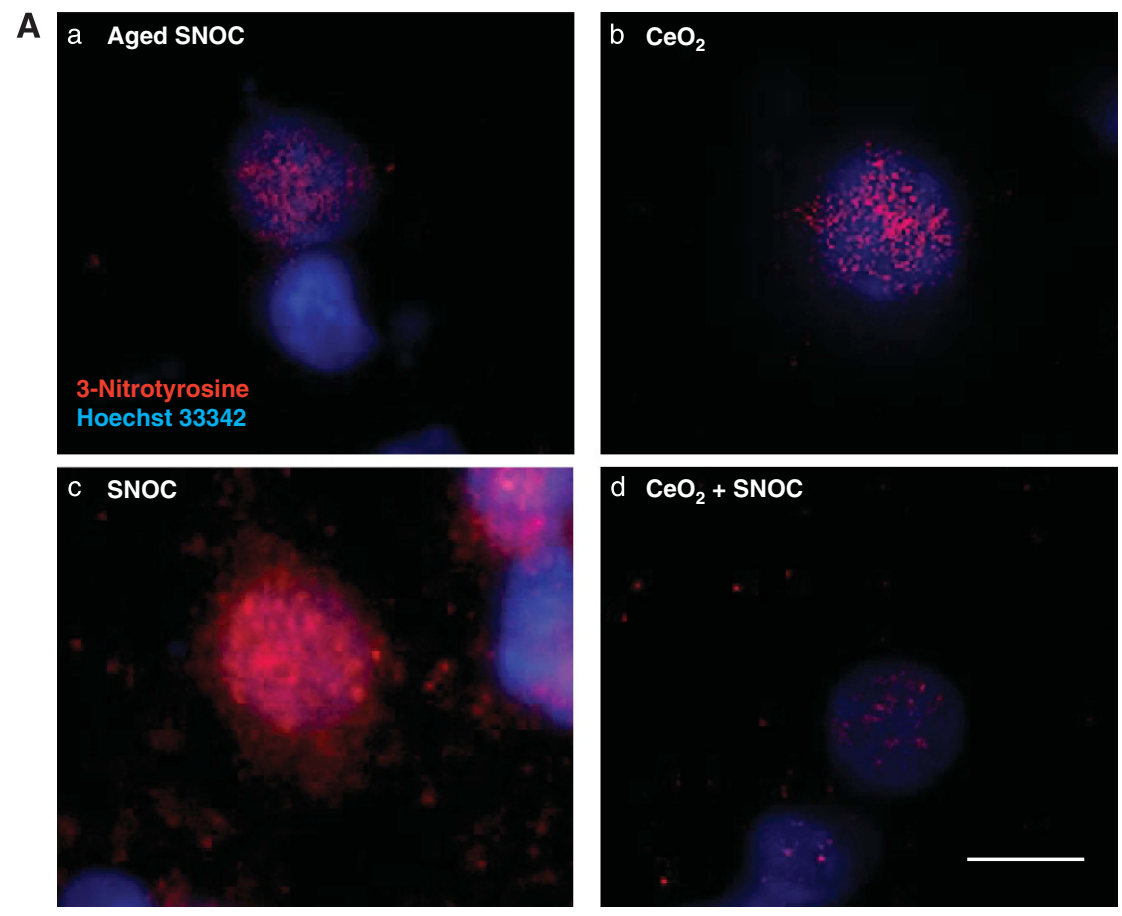

B

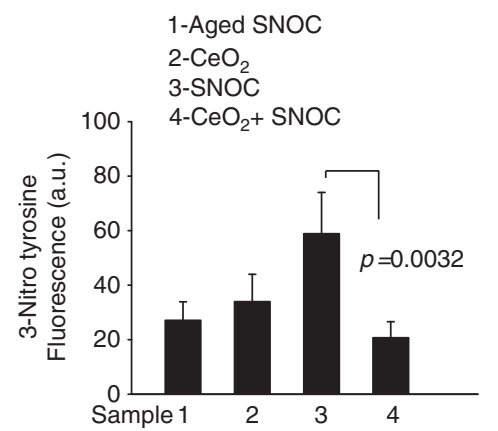

C

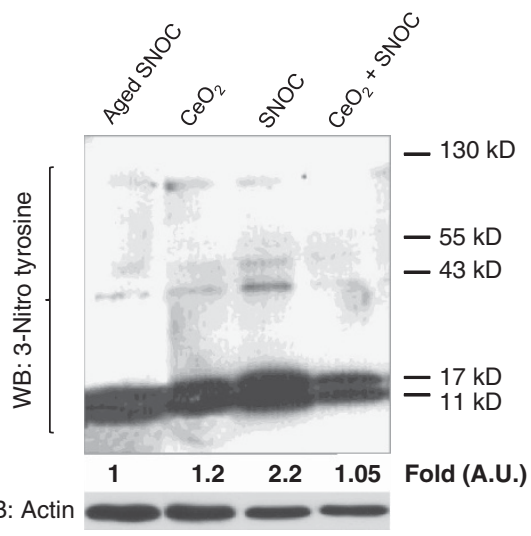

Figure 3 Nanoceria reduce protein tyrosine nitration in SNOC-exposed cortical neurons. (A) Fluorescence micrographs of 3-nitrotyrosine (3-NT; red) immunostaining and Hoechst 33342 (blue) staining of neurons treated with (a) aged SNOC $(100 \mu \mathrm{M})$, (b) nanoceria (100 nM; 3 h pretreatment), (c) fresh SNOC (100 $\mu \mathrm{M})$ or (d) a combination of nanoceria $(100 \mathrm{nM})$ and fresh SNOC $(100 \mu \mathrm{M})$ for $3 \mathrm{~h}$. Scale bar, $10 \mu \mathrm{m}$. (B) 3-NT fluorescence of neurons treated with aged SNOC, nanoceria or fresh SNOC alone or a combination of nanoceria and fresh SNOC for $3 \mathrm{~h}$. Data are means \pm S.D. (C) Western blot of 3-NT protein modification in neurons treated with aged SNOC, nanoceria or fresh SNOC alone or a combination of nanoceria and fresh SNOC for $3 \mathrm{~h}$. Fold densitometries represent the relative ratios of 3-NT in whole neuronal lysates normalized to control lysates. Data are representative of three or more independent experiments. Statistics: Student's t-test

by lowering endogenous peroxynitrite. Neuronal cell death was assessed by chromatin condensation or release of lactate dehydrogenase (LDH). Nanoceria or NAC reduced $\mathrm{A} \beta$-induced neuronal cell death (Figure 6a). Similarly, nanoceria reduced neuronal cell death caused by excess glutamate or NMDA (Figures $6 b-d$ ). Finally, similar protective effects were observed for 3-NP-induced neuronal cell death (Figure 6e).

\section{Discussion}

Nitrosative stress is a characteristic of $A D$ and neurodegeneration; therefore, targeting this event might be beneficial. Several antioxidants including $\beta$-carotene, ascorbate, $\alpha$-tocopherol, glutathione, NAC, coenzyme $Q_{10}$ and tetra- hydrocurcumin exhibited promising effects in AD models. ${ }^{39,40}$ However, they have proven to be, at best, moderately effective in human trials. ${ }^{40,41}$ Poor stability and the need for repetitive dosing might explain, at least in part, the lack of translational effectiveness, underscoring the need for alternative strategies.

To overcome these potential problems, we combined neuroscience with nanotechnology. The goal of this study was to test the effects of inorganic $\mathrm{CeO}_{2}$ nanoparticles, also known as nanoceria, in a cellular model of AD. Because nanoceria can undergo redox cycles and have the potential to regenerate, single dosing might convey lasting, protective effects. To evaluate nanoceria as potential therapeutic antioxidants, we investigated their uptake and subcellular distribution in 

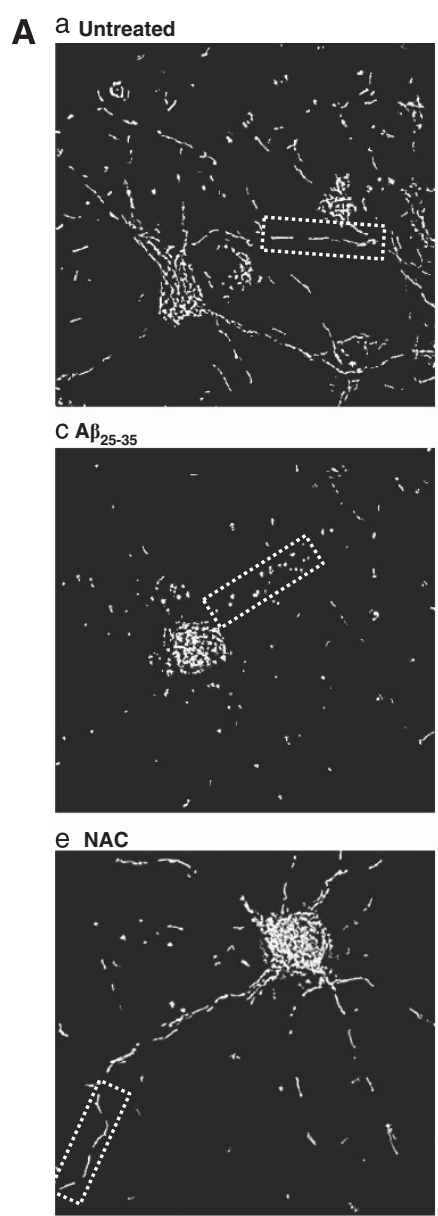

g A $\beta_{35-25}$

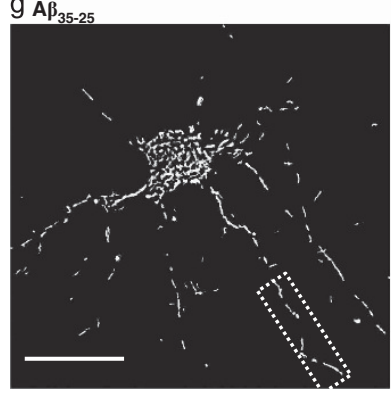

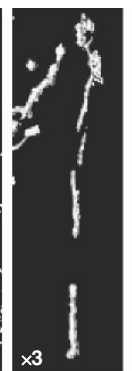
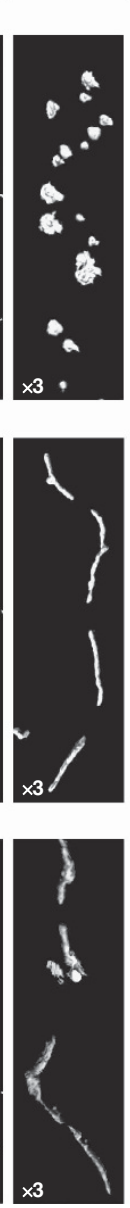

b $\mathrm{CeO}_{2}$

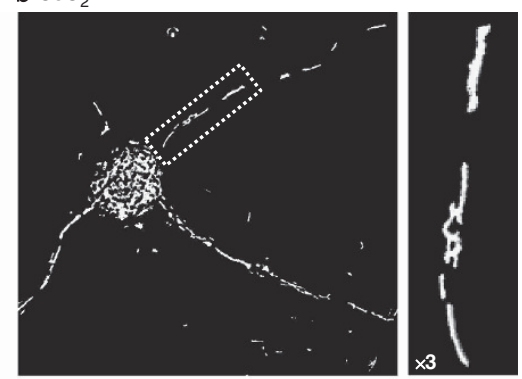

$\mathrm{d} \mathrm{CeO}_{2}+\mathbf{A} \boldsymbol{\beta}_{25-35}$
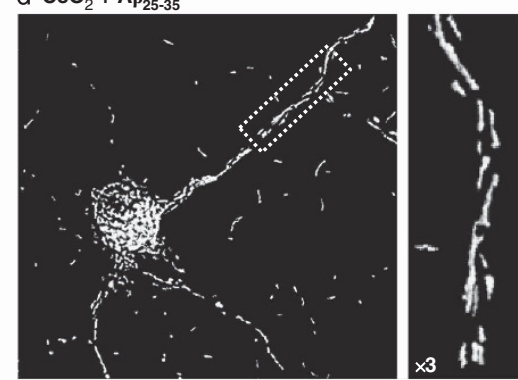

$\mathrm{f} N \mathrm{NC}+\mathbf{A} \boldsymbol{\beta}_{25-35}$
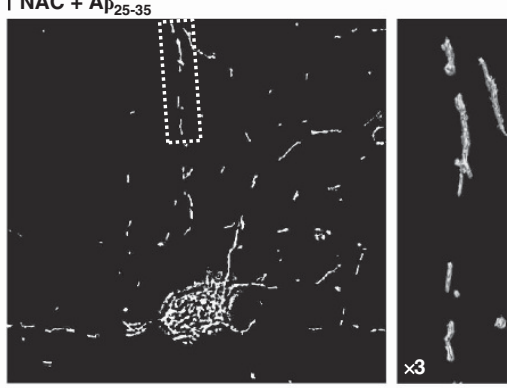

B

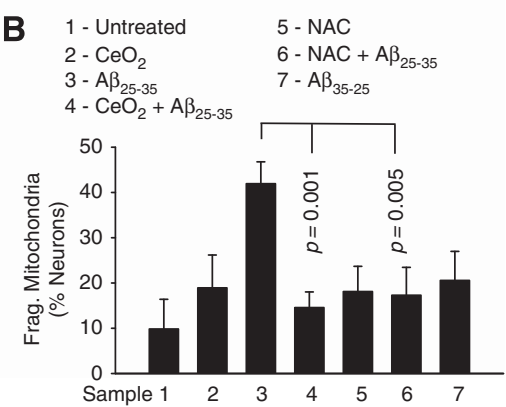

Figure 4 Nanoceria prevent A $\beta$-induced mitochondrial fragmentation. (A) Fluorescence micrographs (scale bar, $50 \mu \mathrm{m}$ ) and $\times 3$ zoom of boxed regions of mitochondrial morphology in neurons expressing DsRed2-Mito that were left untreated (a) or treated with (b) nanoceria (100 nM; $3 \mathrm{~h}$ pretreatment), (c) $\mathrm{A} \beta_{25-35}$ peptide (10 $\left.\mu \mathrm{M}\right)$, (d) nanoceria and $\mathrm{A} \beta_{25-35}$, (e) NAC $\left(50 \mu \mathrm{M}\right.$; $3 \mathrm{~h}$ pretreatment), (f) $N A C$ and $\mathrm{A} \beta_{25-35}$ or $(\mathrm{g}) \mathrm{A} \beta_{35-25}$ peptide $(10 \mu \mathrm{M})$ for $6 \mathrm{~h}$. (B) Mitochondrial fragmentation in neurons expressing DsRed2-Mito after treatment for $6 \mathrm{~h}$ with nanoceria, NAC or $\mathrm{A} \beta_{25-35}$ alone or a combination of nanoceria and $\mathrm{A} \beta_{25-35}$ or NAC and $\mathrm{A} \beta_{25-35}$. Data are representative of three or more independent experiments. Results are means \pm S.D. Statistics: Student's $t$-test

cultured neurons. We found that nanoceria were internalized by neurons within $3 \mathrm{~h}$ (Supplementary Figure $2 \mathrm{a}$ ), which is consistent with other studies (e.g., fluorescein-conjugated nanoceria were internalized by clathrin-mediated endocytosis). ${ }^{36}$ Interestingly, in our study, the particles accumulated at two primary locations: the plasma membrane and mitochondria. With respect to mitochondria, the particles localized to the mitochondrial outer membrane, and thus, might not interact with mitochondrial inner membrane respiratory chain complexes. Our data on mitochondrial localization of nanoceria are in agreement with recent findings in hepatocytes and organotypic hippocampal brain slices. ${ }^{35,42}$

Here we report that nanoceria reduced in situ ROS/RNS, as visualized by decreasing APF oxidation (Figure 2) and 3-nitrotyrosine (3-NT) nitration in both SNOC and $\mathrm{A} \beta_{25-35^{-}}$ stressed neurons (Figures $3 a-C$ ). This is important because increased levels of nitrated proteins have been reported in $A D$ brains and cerebrospinal fluid of AD patients, ${ }^{43}$ and numerous proteins in $A D$ have been shown to be nitrated by peroxynitrite. $^{44}$ For example, peroxisome proliferator-activated 


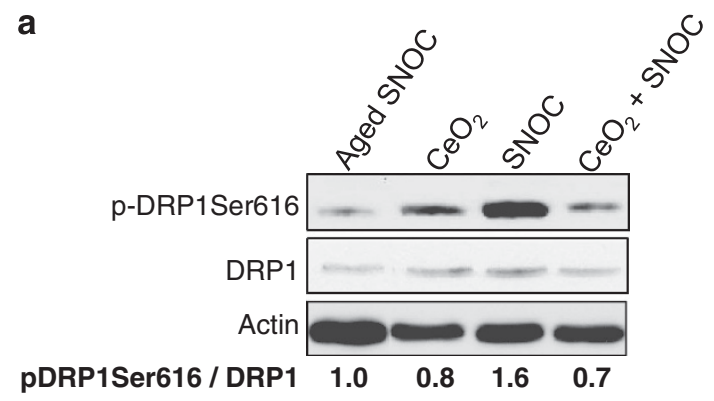

b

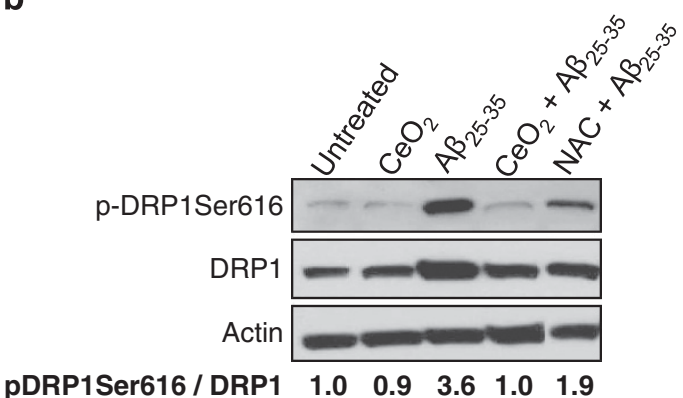

Figure 5 Nanoceria abolish RNS-mediated DRP1 phosphorylation at S616. (a) Western blots of $p$-DRP1 S616, total DRP1 and actin protein levels from neurons exposed for $3 \mathrm{~h}$ to aged SNOC $(100 \mu \mathrm{M})$, nanoceria (100 $\mathrm{nM}$; $3 \mathrm{~h}$ pretreatment) or fresh SNOC $(100 \mu \mathrm{M})$ alone or a combination of nanoceria $(100 \mathrm{nM})$ and fresh SNOC $(100 \mu \mathrm{M})$. Values listed under blots represent relative ratios of p-DRP1 S616 to total DRP1 protein, normalized to actin. (b) Western blots of p-DRP1 S616, total DRP1 and actin protein levels from neurons exposed to nanoceria $(100 \mathrm{nM})$ or pre-aggregated $10 \mu \mathrm{MA} \beta_{25-35}$ alone or in combination for $6 \mathrm{~h}$ or a combination of NAC (50 $\mu \mathrm{M} ; 3 \mathrm{~h}$ pretreatment) and $\mathrm{A} \beta_{25-35}$. Values listed under blots represent relative ratios of $p$-DRP1 $S 616$ to total DRP1 protein normalized to actin

receptor gamma expression protects neurons from $\mathrm{A} \beta$ mediated toxicity; ${ }^{45}$ however, its nitration prevents its translocation to the nucleus, thereby preventing mitochondrial biogenesis. ${ }^{46}$

We also found that nanoceria blocked $\mathrm{A} \beta$-mediated mitochondrial fragmentation via a mechanism that involved reduction of DRP1 S616 hyperphosphorylation (Figure 5b). Although it is unlikely that nitrosative stress mediates mitochondrial fragmentation and neuronal cell death only by phosphorylation of a single protein target, such as DRP1, our data describe one possible pathway by which nanoceria can attenuate the downstream effects of RNS/ROS.

Collectively, our data show that nanoceria were able to ameliorate nitrosative stress and neuronal cell death induced by peroxynitrite, glutamate or $\mathrm{A} \beta$. Our results are consistent with work by others demonstrating cytoprotection by nanoceria. For example, nanoceria decreased nitrosative stress and neuronal cell death in mouse hippocampal brain slices after ischemic injury. ${ }^{35}$ In addition, nanoceria improved the function and survival of rat spinal cord neurons exposed to $\mathrm{H}_{2} \mathrm{O}_{2} \cdot{ }^{47}$ Furthermore, nanoceria protected $\mathrm{HT} 22$ cells, a hippocampal neuronal cell line, from glutamate-induced cell death. ${ }^{48} \mathrm{CeO}_{2}$ nanoparticles also seem to be protective in the eye. Nanoceria decreased oxidative stress in rat retinal neurons in vitro and single intravitreal injections prevented light-induced oxidative damage in albino rats in vivo. ${ }^{49}$ In addition, nanoceria protected against $\mathrm{H}_{2} \mathrm{O}_{2}$-induced cell death in retinal ganglion cells and ROS-induced blindness in vivo. ${ }^{49}$ Nanoceria injections into the vitreous of the eye of very low-density lipoprotein receptor knockout mice, a mouse model of macular degeneration, reduced oxidative stress, tyrosine nitration and VEGF-mediated neovascularization linked to blindness. ${ }^{50}$ Finally, nanoceria might also be cardioprotective as intravenous injection of nanoceria attenuated left ventricle dysfunction and dilation of the heart of monocyte chemo-attractant protein 1 transgenic mice. ${ }^{51}$ This effect was accompanied by a decrease in nitrotyrosine protein modification, inflammatory cytokines and ER stress gene expression. ${ }^{51}$

Although many studies, including the present one, have reported antioxidant and cytoprotective effects of nanoceria, a few studies have provided conflicting data. ${ }^{37,52-54}$ Differences in cell types, tissue context, environmental factors and nanoparticle synthesis and concentration might account for these conflicting findings. Indeed, we observed toxicity at micromolar concentrations (Supplementary Figure 2b). Synthesis methods and surface chemistry are also important factors to consider. Although our preparation of water-based nanoceria produced particles that exhibited SOD-mimetic activity, ${ }^{31,32}$ other synthesis methods might result in nanoceria without comparable antioxidant properties. ${ }^{37}$ However, in addition to differences in synthesis methods and antioxidant activity, the innate complexity of oxygen/nitrogen radical functionality and native stress response systems must be considered when assessing the potential therapeutic value of antioxidants, such as nanoceria.

Although it has long been recognized that oxygen and nitrogen radicals have important roles in cellular processes such as signaling, an emerging topic in the oxidant field is the beneficial role of mild oxidative/nitrosative stress as an inducer of native adaptive responses to reactive species. This phenomenon-in which mild stressors such as caloric restriction and physical exercise induce increased mitochondrial activity, transient ROS formation, and downstream adaptive antioxidant responses-has been documented in multiple model systems. ${ }^{55}$ Thus, an important issue to consider and an alternative explanation for the clinical ineffectiveness of antioxidant therapies to date is disruption of these adaptive response systems. Eradication of the cytoprotective effects of mild stress and undesirable downstream consequences could be particularly problematic for stable, long-acting antioxidants, such as nanoceria. The possibility of such unintended outcomes must be carefully considered and evaluated when preparing antioxidants such as nanoceria for future therapeutic usage.

Finally, the ability to deliver nanoceria to specific cell types and tissues is an important issue, especially across the blood-brain barrier (BBB). Several recent studies have addressed the ability of $\mathrm{CeO}_{2}$ nanoparticles to cross the BBB. ${ }^{56-58}$ In two of these studies, $\mathrm{CeO}_{2}$ nanoparticles were administered intravenously and the concentration of nanoparticles was very low in the normal brain. ${ }^{57,58}$ The study by Kim et al. ${ }^{57}$ used nanoceria that were surface modified with an artificial polymer phospholipid-polyethylene glycol, which is often added to nanoparticles to improve uptake and biodistribution, ${ }^{59}$ yet these particles were also found only in low amounts in brain tissue. However, the ability of 

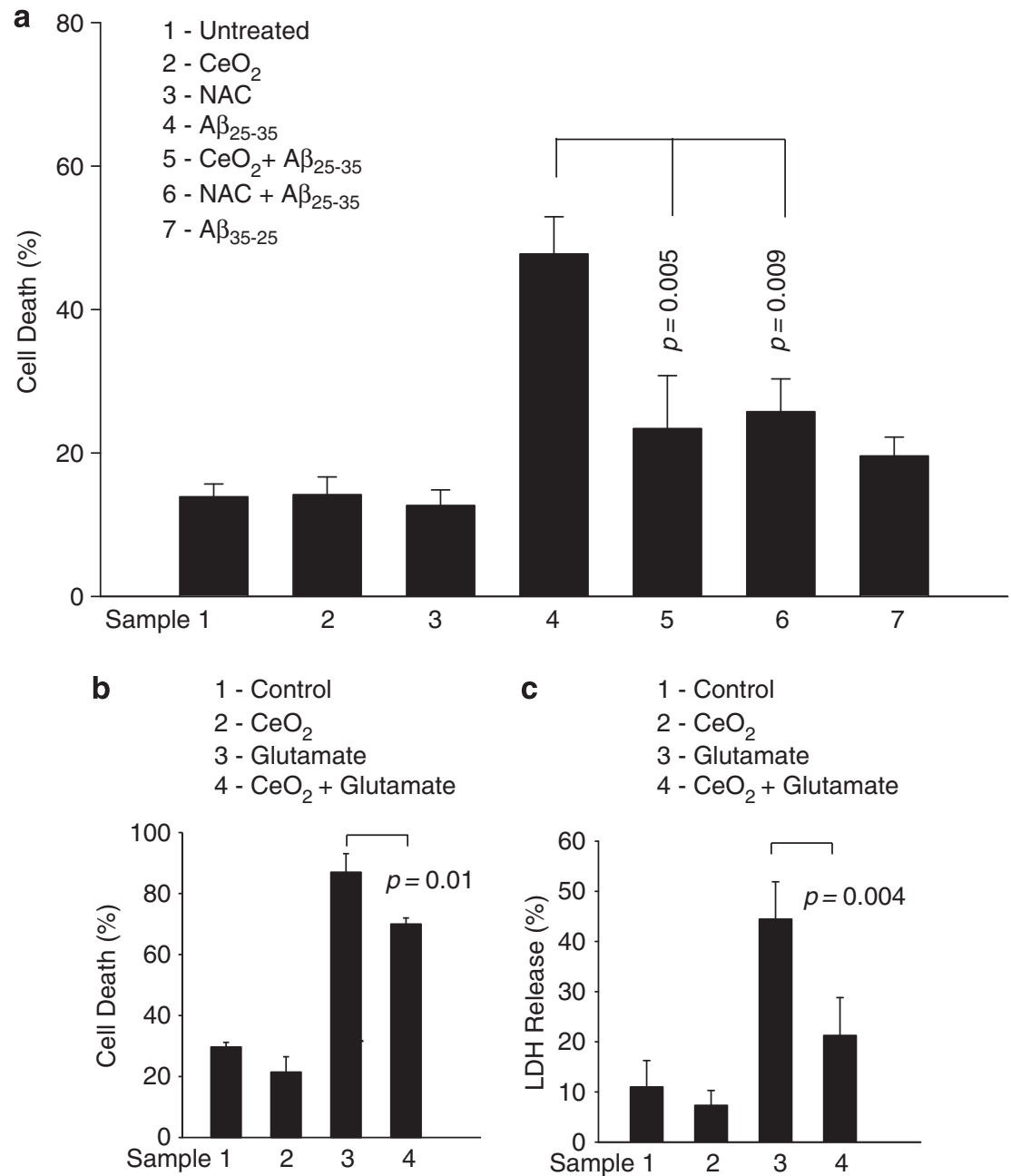
C
1 - Control
$2-\mathrm{CeO}_{2}$
3 - Glutamate
$4-\mathrm{CeO}_{2}+$ Glutamate
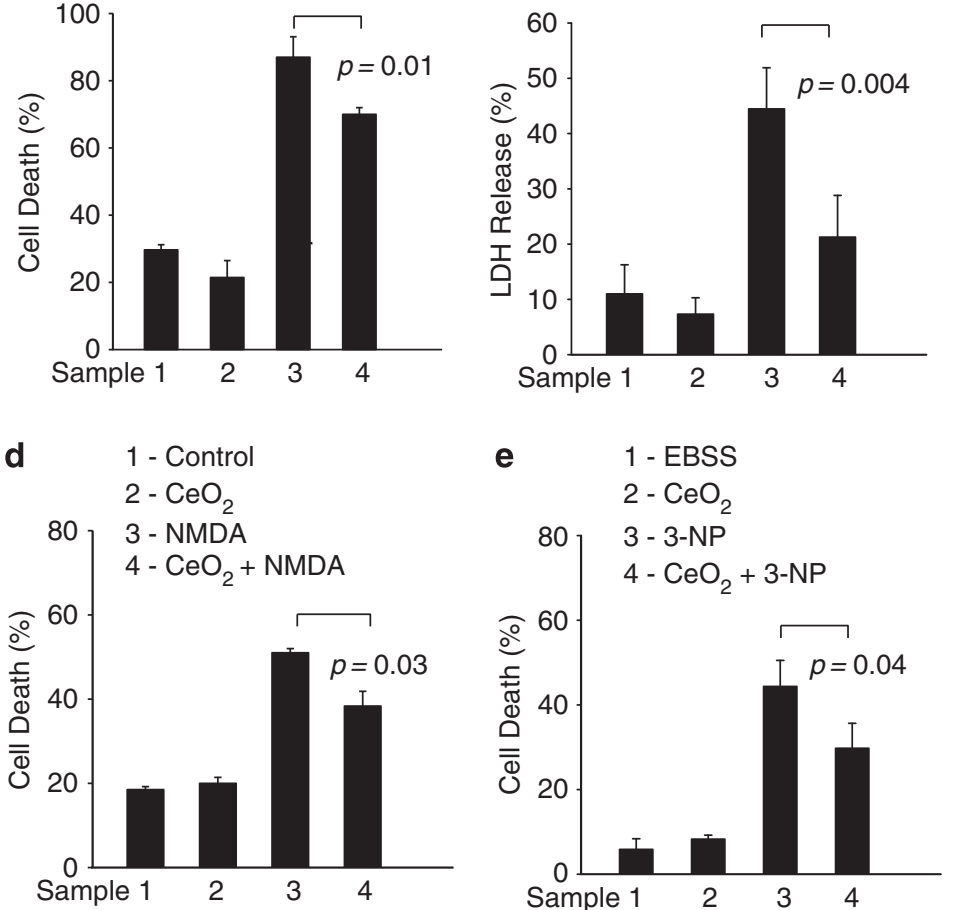

Figure 6 Nanoceria delay neuronal cell death induced by A $\beta$, NMDA, glutamate or 3-NP and reduce LDH release. (a) Cell death of neurons treated with nanoceria ( $100 \mathrm{nM} ; 3 \mathrm{~h}$ pretreatment), NAC $\left(50 \mu \mathrm{M} ; 3 \mathrm{~h}\right.$ pretreatment) or $\mathrm{A} \beta_{25-35}(10 \mu \mathrm{M})$ alone or both nanoceria and $\mathrm{A} \beta_{25-35}$ or NAC and $\mathrm{A} \beta_{25-35}$ for $6 \mathrm{~h}$. Untreated cells or reverse $\mathrm{A} \beta_{35-25}(10 \mu \mathrm{M})$ peptide treatment served as negative controls. (b) Excitotoxic cell death of neurons exposed to glutamate (150 $\left.\mu \mathrm{M}\right)$, nanoceria (100 nM; $3 \mathrm{~h}$ pretreatment) or both for $6 \mathrm{~h}$. (c) LDH release in neurons exposed to glutamate $(200 \mu \mathrm{M})$, nanoceria (100 nM; $24 \mathrm{~h}$ pretreatment) or both for $3 \mathrm{~h}$. (d) Excitotoxic cell death of neurons exposed to NMDA $(150 \mu \mathrm{M})$, nanoceria (100 nM; $3 \mathrm{~h}$ pretreatment) or both for $12 \mathrm{~h}$. (e) Cell death of neurons exposed to mitochondrial respiratory complex II inhibitor $3-\mathrm{NP}$ (10 mM), nanoceria (100 nM; $3 \mathrm{~h}$ pretreatment) or both for $8 \mathrm{~h}$. Results are representative of three or more independent experiments. Data are means \pm S.D. Statistics: Student's $t$-test

nanoparticles to cross the BBB strikingly increased after injury (resulting in increased ROS/RNS). ${ }^{57,58}$ By contrast, another study reported very small $(2.9 \mathrm{~nm}$ diameter $)$, citrate/ EDTA-stabilized $\mathrm{CeO}_{2}$ nanoparticles administered intravenously to healthy rats appeared to cross the intact
$\mathrm{BBB},{ }^{56}$ suggesting that particle modifications might help improve neuronal delivery. In sum, considering the variability in findings to date, efficient delivery of nanoceria to neurons remains an important issue requiring further research and investigation. 
Our results showing that nanoceria protected cortical neurons from multiple nitrosative-associated stressors by preventing mitochondrial fragmentation suggest that these nanoparticles might be an exciting alternative strategy in the development of antioxidant therapeutics. Although important issues related to nanoparticle delivery and overall efficacy of antioxidant therapy in neurodegeneration and aging remain to be addressed, our study represents an important step forward on the path to testing the potential neuroprotective effects of nanoceria in in vivo animal models of $A D$.

\section{Materials and Methods}

Reagents. Earle's Balanced Salt Solution, Hanks buffer, Glutamax, B-27 supplement, Lipofectamine 2000 and penicillin-streptomycin were purchased from Invitrogen (Carlsbad, CA, USA). Neurobasal medium and Dulbecco's Modified Eagle's Medium were purchased from Hyclone (Logan, UT, USA). Poly-L-lysine, HEPES, glutamine, formaldehyde, NAC, anti-3-NT, NMDA, Ponceau S reagent, Durcupan ACM, 3-NP, A $\beta$ peptides and chemicals for $\mathrm{CeO}_{2}$ nanoparticle synthesis were obtained from Sigma-Aldrich (St. Louis, MO, USA). Hoechst 33342, pluronic acid and APF were purchased from Life Technologies (Molecular Probes, Eugene, OR, USA). PVDF membrane was purchased from Bio-Rad Laboratories (Hercules, CA, USA). The DsRed2-Mito vector was obtained from Clontech (Mountain View, CA, USA). Vector Shield was purchased from Vector Laboratories, Inc., (Burlingame, CA, USA). T-Per protein extraction reagent was purchased from Thermo Scientific (Pierce, Rockford, IL, USA). All reagents for TEM were purchased from Ted Pella, Inc. (Redding, CA, USA). The following antibodies were used: monoclonal mouse-anti-DRP1 (clone 8/DLP1, BD Biosciences, San Jose, CA, USA), rabbit polyclonal anti-p-DRP1 S616 (Cell Signaling), rabbit polyclonal 3-NT (Sigma), rabbit $\beta$-actin (Cell Signaling), sheepanti-mouse IgG-HRP (GE Healthcare, Little Chalfont, UK), donkey-anti-rabbit IgG-HRP (GE Healthcare), goat-anti-mouse AlexaFluor488 (Invitrogen) and goat-anti-rabbit AlexaFluor594 (Invitrogen).

Primary cortical neurons. Pure cortical neurons were isolated from Sprague-Dawley rat embryos (E18) as previously described. ${ }^{16,38}$

\begin{abstract}
Mitochondrial fragmentation and neuronal cell death. Neurons were grown on poly-L-lysine-coated glass coverslips as previously described ${ }^{38}$ and transfected with DsRed2-Mito after 5 days in vitro (DIV) using Lipofectamine2000. Where indicated, neurons were pretreated with nanoceria for $3 \mathrm{~h}$. 3-NP was prepared as previously described. ${ }^{38}$ The $A \beta$ peptides were pre-aggregated as previously described. ${ }^{16}$ Cell death was induced with 3-NP $(10 \mathrm{mM}, 8 \mathrm{~h})$, glutamate $(150 \mu \mathrm{M}, 6 \mathrm{~h}), \mathrm{NMDA}(150 \mu \mathrm{M}, 12 \mathrm{~h})$ or $\mathrm{A} \beta(10 \mu \mathrm{M}, 6 \mathrm{~h})$ at $11-14$ DIV or with SNOC $(100 \mu \mathrm{M}, 3 \mathrm{~h})$ at 8 DIV. After various time periods, neurons were fixed using $3.7 \%$ formaldehyde and $5 \%$ sucrose in PBS for $20 \mathrm{~min}$ at $37^{\circ} \mathrm{C}$. Nuclei were labeled with Hoechst $33342(1 \mu \mathrm{g} / \mathrm{ml})$. Quantification of mitochondrial fragmentation and neuronal cell death was performed as previously described. ${ }^{38}$ Fluorescence microscopy and image acquisition of mitochondrial morphology was performed as previously described. ${ }^{60}$
\end{abstract}

LDH activity. LDH release in neurons was measured in the presence of nanoceria for 3,24 and $72 \mathrm{~h}$ and glutamate for $3 \mathrm{~h}(200 \mu \mathrm{M})$ using Cytotoxicity Detection KitPLUS (LDH; Roche Diagnostics, Mannheim, Germany). In short, supernatants from each well were collected and spun to remove cellular debris. Freshly prepared reaction mixture was added and samples were incubated for $15 \mathrm{~min}$ at room temperature (RT) protected from light. Stop solution was added and absorbance was measured at $490 \mathrm{~nm}$. The percentage of toxicity was calculated by including a maximum LDH release control using the following equation: experimental absorbance - control absorbance/maximum release absorbance - control absorbance $\times 100$.

Western blotting. To detect protein nitration, neurons were lysed using T-Per extraction reagent (Thermo Scientific) supplemented with Complete Protease Inhibitor Cocktail (Roche Diagnostics). Protein concentrations were determined using the Bradford assay (Thermo Scientific). Proteins were separated by $4-20 \%$ SDS-PAGE gradient gels (Invitrogen) and transferred to PVDF membranes $(0.2 \mu \mathrm{m}$, Bio-Rad Laboratories). Nonspecific protein binding was blocked by incubating the membranes with TBS $(50 \mathrm{mM}$ Tris- $\mathrm{Cl}, \mathrm{pH} 8.0,150 \mathrm{mM} \mathrm{NaCl})$, $0.02 \%$ Tween 20 and $5 \%$ nonfat milk for $3 \mathrm{~h}$ at RT. The membranes were then probed with primary rabbit polyclonal antibodies for 3-NT (Sigma; 1:500) overnight at $4{ }^{\circ} \mathrm{C}$. After four washes $(5 \mathrm{~min})$ of TBS $(0.02 \%$ Tween 20$)$, membranes were incubated for $2 \mathrm{~h}$ at RT with anti-rabbit horseradish peroxidaseconjugated secondary antibodies (GE Healthcare; $1: 15000$ ) in blocking solution. After four washes ( $5 \mathrm{~min})$ of TBS $(0.02 \%$ Tween 20$)$, immunocomplexes were detected using the Super-Signal West-Dura chemiluminescence substrates (Thermo Scientific). Restore Western Blot Stripping Buffer (Thermo Scientific) was used to strip blots. Membranes were successively probed with anti- $\beta$-actin antibody (Cell Signaling, 1:1000).

To measure the levels of $p$-DRP1 S616, neurons were lysed in buffer containing $50 \mathrm{mM}$ Tris-Cl, pH 7.0, $150 \mathrm{mM} \mathrm{NaCl}, 1 \mathrm{mM} \mathrm{MgCl}, 1 \mathrm{mM} \mathrm{NaF}, 1 \mathrm{mM} \mathrm{NaVO}_{4}, 1 \%$ NP40, 10\% glycerol and complete Protease Inhibitor Cocktail Tablets (Roche Diagnostics). Membranes were blocked with $5 \%$ nonfat milk in TBS (pH 8.0) with $0.05 \%$ Tween 20 for $3 \mathrm{~h}$ at RT and were incubated with primary rabbit polyclonal antibodies for p-DRP1 S616 (Cell Signaling; $1: 1000$ ) overnight at $4{ }^{\circ} \mathrm{C}$. The membranes were then washed four times $(5 \mathrm{~min})$ with TBS $(0.05 \%$ Tween $)$ and incubated for $2 \mathrm{~h}$ at RT with anti-rabbit horseradish peroxidase-conjugated secondary antibodies (GE Healthcare; 1:15000) in blocking solution. After four washes $(5 \mathrm{~min})$ of TBS $(0.05 \%$ Tween), immunocomplexes were then detected using the Super-Signal West-Dura or Femto chemiluminescent substrates (Thermo Scientific). For re-probing, the membranes were stripped with Restore Western Blot Stripping Buffer (Thermo Scientific) according to the manufacturer's instructions and incubated with mouse monoclonal antibodies for DRP1 (BD Biosciences, clone $8 / D L P 1 ; 1: 1000$ ) or with polyclonal rabbit antibodies for $\beta$-actin (Cell Signaling; $1: 1000)$.

Immunocytochemistry for 3-NT. Neurons were grown on poly-L-lysine coated glass coverslips as previously described ${ }^{38}$ and fixed with $4 \%$ formaldehyde (Ted Pella, Inc.) in PBS for $10 \mathrm{~min}$ at RT. Fixed neurons were then permeabilized with $0.1 \%$ Triton X-100 in PBS for 5 min. Nonspecific binding was blocked with $3 \%$ $\mathrm{BSA}$ and $3 \% \mathrm{FBS}$ in PBS for $1 \mathrm{~h}$ at RT. Fixed neurons were then probed with antibodies for 3-NT (1:500, Sigma) and an antibody specific for MAP 2 protein $(1: 200$, Invitrogen; RT, $2 \mathrm{~h})$, a neuronal marker, followed by conjugated fluorescent secondary antibodies, AlexaFluor594 or AlexaFluor488, respectively, at dilutions of $1: 500(\mathrm{RT}, 2 \mathrm{~h})$. Chromatin was stained by incubating fixed samples with Hoechst $33342(1 \mu \mathrm{g} / \mathrm{ml})$ in PBS at RT for $5 \mathrm{~min}$. To visualize 3-NT using AlexaFluor594, the excitation filter was S555/28 × (Chroma, Bellows Falls, VT, USA) and the emission filter was $\$ 617 / 73 \mathrm{~m}$ (Chroma). To visualize neurons using AlexaFluor488, the excitation filter was $\$ 490 / 20 \times$ and the emission filter was S528/38m (Chroma). To visualize Hoechst 33342 , the excitation filter was S403/ $12 \times$ and the emission filter was $\$ 475 / 50 \mathrm{~m}$. Immunostaining conditions for 3-NT were first optimized along with a blocking control using $10 \mathrm{mM}$ nitrotyrosine to confirm specificity of 3-NT signal. Fluorescence microscopy was performed as previously described. ${ }^{11}$ Quantification of fluorescence from 3-NT was as follows. Exposure time, brightness and contrast of randomly selected cortical neurons were held constant for all images within same experiment. Using MetaMorph 7.5, a region of interest was selected around each neuron using the MAP 2 label as a guide. This region was transferred to the 3-NT image channel. The fluorescence intensity for each neuron was measured using Show Region Statistics function. Area and intensity/fluorescence data were logged for each neuron. Neurons (25-50) from each treatment were evaluated for a total of over 100 neurons per experiment. Three areas were selected randomly within each image, and the average of their fluorescence intensity was considered as background. The background was subtracted within each image. 3-NT immunofluorescence quantification is expressed as fluorescence per $\mu \mathrm{m}^{2}$.

APF live-cell imaging. Neurons were cultured on poly-L-lysine-coated MatTek dishes and pretreated with nanoceria for $3 \mathrm{~h}$. To visualize peroxynitrite in neurons, cell permeable APF (2.4 $\mu \mathrm{M}$; Life Technologies, Carlsbad, CA, USA) was loaded in Neurobasal medium (phenol red-free) containing $0.2 \%$ pluronic acid, $1.8 \mathrm{mM} \mathrm{CaCl} 2,0.8 \mathrm{mM} \mathrm{MgCl}_{2}$ and Hoechst $33342(1 \mu \mathrm{g} / \mathrm{ml})$ for $30 \mathrm{~min}$ at $37^{\circ} \mathrm{C}$ in a humidified $5 \% \mathrm{CO}_{2}$ environment. Excess dye was then removed and replaced with conditioned phenol red-free Neurobasal medium. The APF fluorescent signals were measured in response to SNOC $(100 \mu \mathrm{M})$ at $2 \mathrm{~h}$. Z-stacks were acquired keeping the exposure time, brightness and contrast constant using excitation S490/20 $\times$ and emission S528/38m filters (Chroma). Using MetaMorph 7.5 software (Molecular Devices, Sunnyvale, CA, USA), equal backgrounds were 
subtracted from each z-stack image (as determined from each experiment's control images), then z-stack series were summed. Cell soma and processes were selected using a region of interest, as previously described. ${ }^{60}$ This region was transferred to the APF image channel. The fluorescence intensity for each neuron was measured using Show Region Statistics function. Intensity/fluorescence data were logged for each neuron and data were exported to Excel for further analysis.

Nanoceria preparation. Nanoceria were synthesized by a wet chemical process as previously described. ${ }^{61}$ In brief, to prepare nanoceria with a high ratio of $\mathrm{Ce}^{3+} / \mathrm{Ce}^{4+}$, $\mathrm{Ce}\left(\mathrm{NO}_{3}\right)_{3} \quad 6 \mathrm{H}_{2} \mathrm{O}(5 \mathrm{mM})$ was dissolved in $\mathrm{dH}_{2} \mathrm{O}$ and the nitrate precursor was stirred for 15 min then $\mathrm{H}_{2} \mathrm{O}_{2}(2 \% \mathrm{v} / \mathrm{v})$ was rapidly added while stirring at 300 r.p.m. The solution was continuously stirred for $1 \mathrm{~h}$ to obtain a stable dispersion of $\mathrm{CeO}_{2}$ nanoparticles. Samples were stored at RT. All preparations were sonicated to ensure single nanoparticles (Branson, Danbury, CT, USA) for $45-60 \mathrm{~min}$ before use. For cell experiments, nanoceria were diluted in sterile water.

Transmission electron microscopy. Neurons were cultured on poly-L-lysine-coated 35-mm MatTek glass bottom dishes and fixed with $2 \%$ paraformaldehyde, $0.15 \mathrm{M}$ sodium cacodylate, $\mathrm{pH} 7.4,2.5 \%$ glutaraldehyde for $5 \mathrm{~min}$ at RT, followed by an additional $30 \mathrm{~min}$ on ice. The fixed cells were then washed three times with ice-cold $0.15 \mathrm{M}$ sodium cacodylate and $3 \mu \mathrm{M}$ calcium chloride for 3 min on ice, followed by post fixation in 1\% osmium tetroxide, $0.8 \%$ potassium ferrocyanide and $3 \mu \mathrm{M}$ calcium chloride in $0.15 \mathrm{M}$ sodium cacodylate for 60 min on ice. After washing cells three times with ice-cold $\mathrm{ddH}_{2} \mathrm{O}$ for 3 min each, the cultures were stained in $2 \%$ uranyl acetate for 30 min on ice. Samples were dehydrated with ice-cold 20,50,70 and $90 \%$ ethanol and then with $100 \%$ ethanol at RT. The samples were first infiltrated in $50 \%$ ethanol/50\% Durcupan ACM (Fluka/Sigma) for $1 \mathrm{~h}$ at RT and under agitation, followed by three changes of $100 \%$ Durcupan for $3 \mathrm{~h}$. The resin was polymerized at $80^{\circ} \mathrm{C}$ for $3-4$ days under vacuum. Sectioning was performed using $\mathrm{AO} /$ Reichert Ultramicrotome. Ultrathin $(80 \mathrm{~nm})$ sections were post stained with uranyl acetate $(5 \mathrm{~min})$ and lead salts ( $2 \mathrm{~min}$ ) before imaging using a JEOL 1200FX TEM operated at $80 \mathrm{kV}$. A subset of sections was imaged without post staining. Negatives were shot at a magnification of $\times 20000$. The negatives were digitized at 1800 d.p.i. using a Nikon CoolScan system, giving an image size of $4033 \times 6010$ pixels and a pixel resolution of $0.71 \mathrm{~nm}$.

The nanoparticle morphology was characterized using high-resolution TEM (HRTEM). The nanoceria preparation was deposited on the carbon-coated copper grid (SPI supplies) for HRTEM analysis. The TEM grid was dipped into the nanoceria preparation by the dip-coating technique. HRTEM micrographs were obtained using FEI Tecnai F30 operated at $300 \mathrm{keV}$.

X-ray photoelectron spectroscopy. Nanoceria were isolated by centrifugation at 20000 r.p.m using Hermle 220.87 fixed angle rotor in Hermle Z-383K Centrifuge (Cole-Parmer, Vernon Hills, IL, USA) for $20 \mathrm{~min}$ and the pellets were dried and resuspended in $10 \mathrm{mM}$ sodium phosphate buffer, $\mathrm{pH} 7.4,50 \mu \mathrm{M}$ DTPA. Samples were then transferred onto silicon wafers (Kmbh Associates, Rancho Cordova, CA, USA; CZ Silicon, thickness of wafer: $350 \mu \mathrm{m}$ ) and air dried. The surface chemistry of the nanoparticles was studied using a Physical Electronics (5400 PHI ESCA) spectrometer with a monochromatic Al K $\alpha$ X-ray source operated at $300 \mathrm{~W}$ and base pressure of $1 \times 10^{-9}$ Torr. The binding energy of the $\mathrm{Au}(4 \mathrm{f} / \mathrm{2})$ at $84.0 \pm 0.1 \mathrm{eV}$ was used to calibrate the binding energy scale of the spectrometer, and ratios of $\mathrm{Ce}^{3+}$ and $\mathrm{Ce}^{4+}$ in the samples were determined. ${ }^{62,63}$

Statistics. Results were collected from three or more independent experiments and are expressed as mean \pm S.D. Statistical analysis of two populations was compared using two-tailed non-paired Student's t-test.

\section{Conflict of Interest}

The authors declare no conflict of interest.

Acknowledgements. We thank Jin Chen, Sarah Lubitz, Viviana DeAssis, Cory Eldon and Brad Kincaid for their technical assistance; Mason Mackey, NCMIR, UCSD for assistance with EELS; and Andrew Knott for manuscript editing and development. This work is supported by $\mathrm{NIH}$ grants R01NS047456,
R01EY016164 and R01NS055193 (to EB-W); NIH grants 5P41RR004050, P41GM103412-24, P42ES010337 and P01DK54441 (to ME); NIH grant R01AG031529-01 (to WTS and SS); and NSF grant CBET 0708172 (to SS and WTS).

1. Knott $A B$, Bossy-Wetzel $E$. Nitric oxide in health and disease of the nervous system. Antioxid Redox Signal 2009; 11: 541-554.

2. Beal MF. Oxidatively modified proteins in aging and disease. Free Radic Biol Med 2002; 32: 797-803.

3. Good PF, Werner P, Hsu A, Olanow CW, Perl DP. Evidence of neuronal oxidative damage in Alzheimer's disease. Am J Pathol 1996; 149: 21

4. Guix FX, III-Raga G, Bravo R, Nakaya T, de Fabritiis G, Coma M et al. Amyloid-dependent triosephosphate isomerase nitrotyrosination induces glycation and tau fibrillation. Brain 2009; 132(Pt 5): 1335-1345.

5. Guix FX, Wahle T, Vennekens K, Snellinx A, Chavez-Gutierrez L, III-Raga G et al. Modification of gamma-secretase by nitrosative stress links neuronal ageing to sporadic Alzheimer's disease. EMBO Mol Med 2012: 4: 660-673.

6. Kummer MP, Hermes M, Delekarte A, Hammerschmidt T, Kumar S, Terwel D et al. Nitration of tyrosine 10 critically enhances amyloid $\beta$ aggregation and plaque formation. Neuron 2011; 71: 833-844.

7. Smith MA, Richey Harris PL, Sayre LM, Beckman JS, Perry G. Widespread peroxynitritemediated damage in Alzheimer's disease. J Neurosci 1997; 17: 2653-2657.

8. Ghatan S, Larner S, Kinoshita Y, Hetman M, Patel L, Xia Z et al. p38 MAP kinase mediates bax translocation in nitric oxide-induced apoptosis in neurons. J Cell Biol 2000; 150: 335-347.

9. Stamler JS, Lamas S, Fang FC. Nitrosylation. the prototypic redox-based signaling mechanism. Cell 2001; 106: 675-683

10. Aizenman E, Stout AK, Hartnett KA, Dineley KE, McLaughlin B, Reynolds IJ. Induction of neuronal apoptosis by thiol oxidation: putative role of intracellular zinc release. $J$ Neurochem 2000; 75: 1878-1888.

11. Bossy-Wetzel E, Talantova MV, Lee WD, Scholzke MN, Harrop A, Mathews E et al. Crosstalk between nitric oxide and zinc pathways to neuronal cell death involving mitochondrial dysfunction and p38-activated K + channels. Neuron 2004; 41: 351-365.

12. Cuajungco MP, Lees GJ. Nitric oxide generators produce accumulation of chelatable zinc in hippocampal neuronal perikarya. Brain Res 1998; 799: 118-129.

13. Yamamoto T, Maruyama W, Kato Y, Yi H, Shamoto-Nagai M, Tanaka M et al. Selective nitration of mitochondrial complex I by peroxynitrite: involvement in mitochondria dysfunction and cell death of dopaminergic SH-SY5Y cells. J Neural Transm 2002; 109: $1-13$

14. Knott AB, Perkins G, Schwarzenbacher R, Bossy-Wetzel E. Mitochondrial fragmentation in neurodegeneration. Nat Rev Neurosci 2008; 9: 505-518.

15. Swerdlow RH, Burns JM, Khan SM. The Alzheimer's disease mitochondrial cascade hypothesis. J Alzheimers Dis 2010; 20(Suppl 2): S265-S279.

16. Barsoum MJ, Yuan H, Gerencser AA, Liot G, Kushnareva $Y$, Graber $S$ et al. Nitric oxide-induced mitochondrial fission is regulated by dynamin-related GTPases in neurons. EMBO J 2006; 25: 3900-3911.

17. Gan X, Huang S, Wu L, Wang Y, Hu G, Li G et al. Inhibition of ERK-DLP1 signaling and mitochondrial division alleviates mitochondrial dysfunction in Alzheimer's disease cybrid cell. Biochim Biophys Acta 2014; 1842: 220-231.

18. Manczak M, Calkins MJ, Reddy PH. Impaired mitochondrial dynamics and abnormal interaction of amyloid beta with mitochondrial protein Drp1 in neurons from patients with Alzheimer's disease: implications for neuronal damage. Hum Mol Genet 2011; 20: 2495-2509.

19. Smirnova E, Griparic L, Shurland DL, van der Bliek AM. Dynamin-related protein Drp1 is required for mitochondrial division in mammalian cells. Mol Biol Cell 2001; 12: 2245-2256.

20. Cho DH, Nakamura T, Fang J, Cieplak P, Godzik A, Gu Z et al. S-nitrosylation of Drp1 mediates beta-amyloid-related mitochondrial fission and neuronal injury. Science 2009; 324: 102-105

21. Bossy B, Petrilli A, Klinglmayr E, Chen J, Lutz-Meindl U, Knott AB et al. S-Nitrosylation of DRP1 does not affect enzymatic activity and is not specific to Alzheimer's disease. J Alzheimers Dis 2010; 20(Suppl 2): S513-S526.

22. Wang X, Su B, Lee HG, Li X, Perry G, Smith MA et al. Impaired balance of mitochondrial fission and fusion in Alzheimer's disease. J Neurosci 2009; 29: 9090-9103.

23. Taguchi N, Ishihara N, Jofuku A, Oka T, Mihara K. Mitotic phosphorylation of dynamin-related GTPase Drp1 participates in mitochondrial fission. J Biol Chem 2007; 282: $11521-11529$

24. Strack S, Wilson TJ, Cribbs JT. Cyclin-dependent kinases regulate splice-specific targeting of dynamin-related protein 1 to microtubules. J Cell Biol 2013; 201: 1037-1051.

25. Crews L, Masliah E. Molecular mechanisms of neurodegeneration in Alzheimer's disease. Hum Mol Genet 2010; 19: R12-R20.

26. Murakami K, Murata N, Noda Y, Tahara S, Kaneko T, Kinoshita N et al. SOD1 (copper/zinc superoxide dismutase) deficiency drives amyloid beta protein oligomerization and memory loss in mouse model of Alzheimer disease. J Biol Chem 2011; 286: 44557-44568.

27. Richardson JS. Free radicals in the genesis of Alzheimer's Disease. Ann N Y Acad Sci 1993; 695: 73-76. 
28. Esposito L, Raber J, Kekonius L, Yan F, Yu G-Q, Bien-Ly N et al. Reduction in mitochondrial superoxide dismutase modulates Alzheimer's disease-like pathology and accelerates the onset of behavioral changes in human amyloid precursor protein transgenic mice. J Neurosci 2006; 26: 5167-5179.

29. Massaad CA, Washington TM, Pautler RG, Klann E. Overexpression of SOD-2 reduces hippocampal superoxide and prevents memory deficits in a mouse model of Alzheimer's disease. Proc Natl Acad Sci USA 2009; 106: 13576-13581.

30. Esch F, Fabris S, Zhou L, Montini T, Africh C, Fornasiero P et al. Electron localization determines defect formation on ceria substrates. Science 2005; 309: 752-755.

31. Heckert EG, Karakoti AS, Seal S, Self WT. The role of cerium redox state in the SOD mimetic activity of nanoceria. Biomaterials 2008; 29: 2705-2709.

32. Korsvik C, Patil S, Seal S, Self WT. Superoxide dismutase mimetic properties exhibited by vacancy engineered ceria nanoparticles. Chem Commun 2007; 10: 1056-1058.

33. Pirmohamed T, Dowding JM, Singh S, Wasserman B, Heckert E, Karakoti AS et al. Nanoceria exhibit redox state-dependent catalase mimetic activity. Chem Commun (Camb) 2010; 46: 2736-2738.

34. Dowding JM, Dosani T, Kumar A, Seal S, Self WT. Cerium oxide nanoparticles scavenge nitric oxide radical (NO). Chem Commun (Camb) 2012; 48: 4896-4898.

35. Estevez AY, Pritchard S, Harper K, Aston JW, Lynch A, Lucky JJ et al. Neuroprotective mechanisms of cerium oxide nanoparticles in a mouse hippocampal brain slice model of ischemia. Free Radic Biol Med 2011; 51: 1155-1163.

36. Singh S, Kumar A, Karakoti A, Seal S, Self WT. Unveiling the mechanism of uptake and sub-cellular distribution of cerium oxide nanoparticles. Mol Biosyst 2010; 6: 1813-1820.

37. Karakoti AS, Munusamy P, Hostetler K, Kodali V, Kuchibhatla S, Orr G et al. Preparation and characterization challenges to understanding environmental and biological impacts of nanoparticles. Surf Interface Anal 2012; 44: 882-889.

38. Liot G, Bossy B, Lubitz S, Kushnareva Y, Sejbuk N, Bossy-Wetzel E. Complex II inhibition by 3-NP causes mitochondrial fragmentation and neuronal cell death via an NMDA- and ROS-dependent pathway. Cell Death Differ 2009; 16: 899-909.

39. Chaturvedi RK, Beal MF. Mitochondrial approaches for neuroprotection. Ann N Y Acad Sci 2008; 1147: 395-412.

40. Gilgun-Sherki Y, Melamed E, Offen D. Oxidative stress induced-neurodegenerative diseases: the need for antioxidants that penetrate the blood brain barrier. Neuropharmacology 2001; 40: 959-975.

41. Frei B. Efficacy of dietary antioxidants to prevent oxidative damage and inhibit chronic disease. J Nutr 2004; 134: 3196S-3198S.

42. Amin KA, Hassan MS, Awad el ST, Hashem KS. The protective effects of cerium oxide nanoparticles against hepatic oxidative damage induced by monocrotaline. Int $J$ Nanomed 2011; 6: 143-149.

43. Tohgi $\mathrm{H}$, Abe T, Yamazaki K, Murata T, Ishizaki E, Isobe C. Alterations of 3-nitrotyrosine concentration in the cerebrospinal fluid during aging and in patients with Alzheimer's disease. Neurosci Lett 1999; 269: 52-54.

44. Pacher P, Beckman JS, Liaudet L. Nitric oxide and peroxynitrite in health and disease. Physiol Rev 2007; 87: 315-424.

45. Fuenzalida K, Quintanilla R, Ramos P, Piderit D, Fuentealba RA, Martinez G et al. Peroxisome proliferator-activated receptor gamma up-regulates the $\mathrm{Bcl}-2$ anti-apoptotic protein in neurons and induces mitochondrial stabilization and protection against oxidative stress and apoptosis. J Biol Chem 2007; 282: 37006-37015.
46. Shibuya A, Wada K, Nakajima A, Saeki M, Katayama K, Mayumi $T$ et al. Nitration of PPARgamma inhibits ligand-dependent translocation into the nucleus in a macrophage-like cell line, RAW 264. FEBS Lett 2002; 525: 43-47.

47. Das M, Patil S, Bhargava N, Kang JF, Riedel LM, Seal S et al. Auto-catalytic ceria nanoparticles offer neuroprotection to adult rat spinal cord neurons. Biomaterials 2007; 28: 1918-1925.

48. Schubert D, Dargusch R, Raitano J, Chan SW. Cerium and yttrium oxide nanoparticles are neuroprotective. Biochem Biophys Res Commun 2006; 342: 86-91.

49. Chen J, Patil S, Seal S, McGinnis JF. Rare earth nanoparticles prevent retinal degeneration induced by intracellular peroxides. Nat Nanotechnol 2006; 1: 142-150.

50. Zhou X, Wong LL, Karakoti AS, Seal S, McGinnis JF. Nanoceria inhibit the development and promote the regression of pathologic retinal neovascularization in the VIdlr knockout mouse. PLoS One 2011; 6: e16733.

51. Niu J, Azfer A, Rogers LM, Wang X, Kolattukudy PE. Cardioprotective effects of cerium oxide nanoparticles in a transgenic murine model of cardiomyopathy. Cardiovasc Res 2007; 73: 549-559.

52. Arnold MC, Badireddy AR, Wiesner MR, Di Giulio RT, Meyer JN. Cerium oxide nanoparticles are more toxic than equimolar bulk cerium oxide in Caenorhabditis elegans. Arch Environ Contam Toxicol 2013; 65: 224-233.

53. Cheng G, Guo W, Han L, Chen E, Kong L, Wang L et al. Cerium oxide nanoparticles induce cytotoxicity in human hepatoma SMMC-7721 cells via oxidative stress and the activation of MAPK signaling pathways. Toxicol In Vitro 2013; 27: 1082-1088.

54. Kumari M, Singh SP, Chinde S, Rahman MF, Mahboob M, Grover P. Toxicity study of cerium oxide nanoparticles in human neuroblastoma cells. Int $J$ Toxicol 2014; 33: 86-97.

55. Ristow M, Schmeisser S. Extending life span by increasing oxidative stress. Free Radic Biol Med 2011; 51: 327-336.

56. Heckman KL, DeCoteau W, Estevez A, Reed KJ, Costanzo W, Sanford D et al. Custom cerium oxide nanoparticles protect against a free radical mediated autoimmune degenerative disease in the brain. ACS Nano 2013; 7: 10582-10596.

57. Kim CK, Kim T, Choi IY, Soh M, Kim D, Kim YJ et al. Ceria nanoparticles that can protect against ischemic stroke. Angew Chem Int Ed Engl 2012; 51: 11039-11043.

58. Yokel RA, Au TC, MacPhail R, Hardas SS, Butterfield DA, Sultana R et al. Distribution, elimination, and biopersistence to 90 days of a systemically introduced $30 \mathrm{~nm}$ ceriaengineered nanomaterial in rats. Toxicol Sci 2012; 127: 256-268.

59. Karakoti AS, Das S, Thevuthasan S, Seal S. PEGylated inorganic nanoparticles. Angew Chem Int Ed Engl 2011; 50: 1980-1994.

60. Song W, Bossy B, Martin OJ, Hicks A, Lubitz S, Knott AB et al. Assessing mitochondrial morphology and dynamics using fluorescence wide-field microscopy and $3 \mathrm{D}$ image processing. Methods 2008; 46: 295-303.

61. Patil S, Kuiry SC, Seal S, Vanfleet R. Synthesis of nanocrystalline ceria particles for high temperature oxidation resistant coating. J Nanopart Res 2002; 4: 433-438.

62. Burroughs P, Hamnett A, Orchard AF, Thornton G. Satellite structure in X-Ray photoelectron-spectra of some binary and mixed oxides of lanthanum and cerium. J Chem Soc Dalton Trans 1976; 17: 1686-1698.

63. Romeo M, Bak K, Elfallah J, Lenormand F, Hilaire L. Xps study of the reduction of cerium dioxide. Surf Interface Anal 1993; 20: 508-512.

Supplementary Information accompanies this paper on Cell Death and Differentiation website (http://www.nature.com/cdd) 